\title{
Hearing and Aids to Hearing
}

$\mathrm{D}$ URING the discussion on "Hearing and Hearing Aids" held by Sections J (Psychology) and I (Physiology) of the British Association in Norwich on September 5, the major point considered was the effect of intense stimuli upon the performance of normal and deaf ears. The matter was approached from two points of view; of the increase of intelligibility of speech, when amplified, for partially deaf patients, and of the effect of listening to loud pure tones upon the acuity of pure tone hearing in both normal and partially deaf ears.

Dr. A. W. G. Ewing and Mr. T. S. Littler, of the Department of Education of the Deaf, University of Manchester, first described the apparatus which they are using for investigating the first of these points. This consists of a microphone and amplifier situated in a small sound-proofed room. The output of the amplifier passes via a decibel attenuator to the reproducing system. In this way, the intensity of the sound applied to the observer's ear by speaking into the microphone can be varied at will from a subnormal loudness to one of 110 decibels above the normal threshold. The power-level reached at any moment can be read from an output meter connected in the outgoing power-line.

Dr. Ewing then dealt with the effect of amplifying speech by these means upon its intelligibility for partially deaf observers. He showed, for example, that out of eight such observers, for five the intelligibility could reach 100 per cent. Of these five, two required an intensity level of 110 decibels, and the remainder required 70-90 decibels. In a control experiment upon normal subjects, 100 per cent intelligibility could not be achieved with loudnesses greater than 70 decibels; the intelligibility tests employed were of normal speech one foot from the microphone, and of 20 consonant sounds specially chosen.

Whilst it is clear that the number of observers used is too small to permit of any generalisation with regard to the deaf population as a whole, it is none the less a remarkable fact that more than half of these cases were enabled to hear speech, under amplified conditions, almost perfectly. Dr. Ewing stressed the fact that these results were obtained under laboratory conditions-it is clearly unlikely that so favourable an effect would be found when using any of the easily portable aids to hearing at present available. It must also be stressed that in these experiments, background noise, so evident when using a normal hearing aid, where it arises from defects inherent in the apparatus itself as well as from the more important source of the extraneous noise present in any normal environment, has been reduced to a minimum. The installation of the microphone in a sound-proof room, to take but one example of special precautions, would clearly be quite out of the question with a portable deaf-aid.

In the discussion at the end of the meeting Major Tucker, of the R.A.F. Research Establishment, Biggin Hill, raised an interesting point with reference to this paper. When listening to speech at very high intensities, he pointed out, the intelligibility is often lowered by masking of high-frequency (consonant) sounds by low-frequency (vowel) sounds. He suggested the possibility of increasing the intelligibility of much amplified speech by the introduction of suitable high-pass filters into the system. He pointed out that at least an experiment on these lines might be worth trying. Mrs. Ewing disagreed about the desirability of doing this, on the grounds that it might lead to distortion of a partially deaf child's speech. Mr. Littler also disagreed, on the grounds, among others, that if low tones are led to one ear and high tones to the other, a peculiar sensation that the sound is spinning round the head was sometimes experienced.

In his paper, Mr. A. F. Rawdon-Smith discussed somewhat different aspects of deafness. He described an apparatus, installed in the Psychological Laboratory, University of Cambridge, with which it is possible to produce very pure tones of great and controllable intensity, and of frequencies throughout almost the whole of the auditory spectrum. The apparatus is used for investigating the phenomena of experimental deafness, and consists of a beat-tone oscillator, amplifiers and attenuators, together with subsidiary frequency checking and monitoring apparatus; sinusoidal voltages from this equipment are led to a moving-coil ear-piece, situated in a highly sound-proof room. With this equipment, the modification of the normal audiogram by listening to intense pure tones for periods up to five minutes has been investigated. If sufficiently intense, such tones lead to a very considerable, though temporary, loss of acuity. Mr. Rawdon-Smith demonstrated that this acuity loss is not confined to the single ear stimulated-on many occasions a loss of acuity almost as great has been found in the ear nominally unstimulated. This, together with the fact that the losses in both ears may sometimes be temporarily removed or lessened by subjecting the observer to an unexpected stimulus, such as momentarily switching off the lights in the sound-proof room, has led him to the conclusion that these losses, usually referred to as being due to auditory fatigue, are partly of cortical mediation. Undoubtedly, peripheral fatigue losses do occur also, as it is possible to show that, in the mammalian ear preparation, using Davis and Saul's method of recording the electrical activity of the auditory mid-brain, a peripheral sensitivity loss occurs; this has been found using the mid-brain action potential (not to be confused with the Wever and Bray (cochlear) effect) as an index of auditory function. The phenomenon of experimental deafness can be regarded, therefore, as of dual origin-in part peripheral, which may be termed auditory fatigue, and in greater part of cortical mediation, for which auditory inhibition is the preferred terminology.

At the end of his paper, Dr. Ewing produced interesting evidence that such partially deaf patients as he has tested are immune from either of these effects; in short, the production of temporarily increased deafness in the already deaf, by listening to loud pure tones or to much amplified speech, even for relatively long periods of time, is impossible.

It is regretted that exigencies of space do not permit of a more detailed discussion of the remaining two papers. If the author has devoted overmuch 
space to those already considered, it is only because he is necessarily more familiar with that material.

Dr. P. M. T. Kerridge dealt with the history and causes of deafness in London children in schools for the deaf. It is interesting to note from her analysis that, in the severely deaf group, almost half had been deaf from birth. Miss E. L. S. Ross discussed and analysed the results of an experiment in which a short story was read to two small groups of partially or severely deaf children, first without and secondly with an electrical aid of commercial manufacture. The children's reproductions of this story were marked according as they had, for example, grasped or missed the point, or understood or misunderstood the name of the central character. She showed that only with some of the children was a partial improvement of understanding secured by these means.

A. F. RAWDON-SMITH.

\section{Ability, Opportunity and Social Status}

$\mathrm{I}^{\mathrm{N}}$ $\mathrm{N}$ a paper entitled "Ability and Educational Opportunity in Relation to Parental Occupation", which appears in the Sociological Review (27, No. 3, July 1935), J. L. Gray and Pearl Moshinsky bring forward evidence to show that the children of the less prosperous social classes lack the opportunity for higher education available to the equally able children of the financially prosperous classes. The investigation on which the evidence is based was carried out on nearly 9,000 children, between the ages of 9 years and 12 years 6 months, drawn from primary, post-primary (including central), grantaided secondary, private, and preparatory schools in the London area, during the year 1933-34. Individual ability was assessed by the Otis Advanced Group Intelligence Test (Form $A$ ), and each child was questioned individually regarding parental occupation.

The authors point out that every attempt at morphological classification in social orders presupposes a social philosophy and a knowledge of the causes of social differentiation. The classification finally adopted by them represents a compromise between several current systems. The basis of group differences is taken as the nature of the work performed, but is modified "where it seemed advisable" by combination with differences in average income and in social status: the six main groups thus obtained are relatively homogeneous. They are: $(A)$ Employing and Directive Classes; (B) Professional Classes ; $(C)$ Minor Professional and Other Highly Skilled Occupations ; $(D)$ Clerical and Commercial Employees; $(E)$ Manual Workers; and $(F)$ Miscellaneous Workers and Unknown Occupations.

The significant differences in educational opportunity between these socio-economic categories, revealed by the final analysis, certainly confirm the authors' belief that the groups do constitute real socio-economic strata.

It is evident that this classification correlates to some extent both with parental intelligence and with nurtural and environmental factors in the life of the child. The acceptance of the genetic evidence that highly intelligent parents tend to produce highly intelligent children, or the acceptance of the doctrine that nurture is the dominant factor in intellectual development, leads to the expectation of a small positive correlation between the intelligence of the child population examined and the parental socio-economic status. The value found by the authors is $0.25 \pm 0.008$, a value which is, however, too small to be used diagnostically. This value compares favourably with the value $0 \cdot 28$ found by Duff and Thompson* in an investigation of the

* Brit. J. Psychol., 14, Pt. 2; 1924. parallel problem in Northumberland ten years ago. As the authors state (but not only for the reasons quoted) it is unwarranted to assert, by reason of the existence of the positive correlation, that intelligence is causally related to parental socio-economic status.

Some of the results of the primary analysis deserve special reference :

(1) In all cases, the children of teachers of every kind exceed the mean of the social group of highest intelligence. This is, perhaps, not surprising in view of the construction of the test used to obtain differentiæ.

(2) The children of the 'larger business owners and higher executives group' are significantly inferior in mean intelligence to those of the professional classes. Nearly every other investigator has arrived at this conclusion.

(3) It is probable that children of manual workers engaged in the newer industries, where, for example, considerable mechanical ability is demanded, are superior in mean intelligence to those of all manual workers.

(4) The children of unskilled workers form a remarkably homogeneous group.

In the ultimate analysis of their material, the authors make a comparative study of the distribution among the various social orders of the opportunity for higher education and of the corresponding distribution of high ability, that is, ability to benefit from higher education, the lower level being taken at 130 I.Q. on the Otis scale or 120 I.B. (Index of Brightness) on the authors' scale. As a source of children of high ability, the 'manual workers group' is the largest numerically, although it contains the smallest percentage of able children within the group. Thus, 58 per cent of the children of the 'professional classes group' possess ability, and 23 per cent of the children of 'manual workers group' are equally able; but in terms of the ratio of able children in the group to the total of all able children, these figures are 5 per cent and 50 per cent.

The discrepancies between ability and opportunity are shown by the following figures : 95 per cent of the able children of the 'professional classes group' have the opportunity for higher education; 48 per cent of the able children of the 'clerical and commercial employees group' have the same opportunity ; only 25 per cent of the able children of the 'manual workers group' receive the same facilities. Opportunity for higher education is wasted most by the children of the 'larger business owners and higher executives' and of the 'professional classes groups'. There are 49 per cent of the former and 35 per cent of the latter, in each group, with opportunity but 